\title{
Research of the spillover effect and cost control of industrial transfer
}

\author{
Dong Jianping \\ Department of Finance, Tianjin Agricultural University, Tianjin 300384 \\ dongjianping68@163.com
}

Keywords: Industrial transfer; spillover effect; cost; control

\begin{abstract}
With the rapid growth of China's economy, the imbalance of regional economic has become increasingly apparent. The economic gap among east, central and western region is widening. In order to adjust the economic structure, the industrial transfer among different regions should be accelerated. The undertaking regions for the industrial transfer, however, focus too much on the technology spillover effect, therefore, usually underestimate the transfer cost, even ignore the negative influence of the industrial transfer on environment. In this paper, the effects of industrial transfer on both transfer and undertaking regions are analyzed, and the controlling measures for the transfer cost are put forward. The results provide the beneficial suggestions for the coordination development of regional economy.
\end{abstract}

\section{Introduction}

With the rapid growth of China's economy, the structural problems in economic development is increasingly apparent, which show that the regional economic development is imbalance, the economic gap, production cost and consumption level among east, central and western region is widening. At present, the economy aggregate of 11 provinces in eastern part occupies $60 \%$ of the whole country, especially in Guangdong province, its contribution is more than $10 \%$ of the China's economy ${ }^{[1-2]}$. With the rapid economic development in the eastern China, the price of the production factors such as land and labor power increase continually, the supplies of resources and energy are tight, and the contradiction between ecological protection and energy conservation become evident. The industries in eastern part of China belong to the resource-intensive industries and labor-intensive industries, the problems mentioned above force the eastern industries to move to outside regions. The economic development in western China is relatively backward, and the economy aggregate is low, therefore, it needs to adjust the economic structure with the help of domestic and international industry transfer.

The industrial transfer refers to a process of certain industries transfer from one country or region to another country or region ${ }^{[3]}$, and it is a kind of widespread economic phenomenon in the process of economic development. Through the industrial transfer, the economy and social resources among different industries and different regions can be relocated, enabling the utility of the scarce resources to be used optimally.

In recent years, Chinese government guides the industrial transfer from the east to the west. At the same time, the western provinces are actively undertaking the industrial transfer from the eastern provinces in order to improve their level of technology innovation and reduce the economic gap between the eastern and western regions. However, in the process of industrial transfer, the undertaking regions emphasize too much the technology spillover effect of industrial transfer, underestimate the transfer cost, even ignore the negative influence of the industrial transfer on 
environment, resulting in a high cost of follow-up management. In this paper, the effects of industrial transfer on both transfer and undertaking regions are analyzed, and the controlling measures for the transfer cost are put forward. The results provide the beneficial suggestions for the coordination development of regional economy.

\section{Characteristics of industrial transfer and its spillover effect}

\subsection{Characteristics of industrial transfer}

Because of the economic development and the progress of technology, the transportation, environmental resource, market demands and government policies began to change, leading to the industrial transfer from one region to another region. The industrial transfer promotes the flow of production factors, for example, the aggregate investment in one region increases or decreases, the field of investment changes from one industry to another industry. In general, the industrial transfer has several characteristics as follows ${ }^{[4-5]}$ :

First, the industrial transfer has the characteristic with different levels. The industrial transfer can be the transfer of whole industry; also can be one part of the industrial chain. Second, the industrial transfer includes different stages. The industrial transfer within a country is consistent with the upgrading of regional industrial structure. The labor intensive industry transfer to the capital intensive industry, then to the technology intensive industry. Third, the industrial transfer has gradient diffusivity. Whether all over the world or within one country, there are multi-level unbalanced differences among countries or regions. Accordingly, a specific industry usually transfers from the developed region to less developed region, then to transfer to underdeveloped region. , this industrial transfer has a characteristic of the gradient diffusivity. Fourth, the manufacturing industry is the centre of the industrial transfer. The reason is that the manufacturing industry is the main carrier of technological progress and technological transformation, therefore, the technological progress in this field is the fastest, and the structure change is the largest. Experience around the world has shown that the scale and scope of transfer of manufacturing industry is the most widely.

\section{2 The spillover effect of industrial transfer}

The technology spillover effect of industry transfer mainly refers that the industrial transfer promotes the technological progress and labor productivity of the undertaking region. The spillover effect of industry transfer play a role through four ways, i.e., demonstration, market competition, associated driving, and human capital flow ${ }^{[6]}$. However, the spillover effect of industrial transfer between transferred region and accepted region is different ${ }^{[7]}$.

(1) Effect of industrial transfer on the transferred region. As far as the transferred region is concerned, the result of the industrial transfer leads to a decline in the production capacity. After the industrial transfer is completed, the number of people employed in the industry drops, and the industrial competitiveness reduces. However, generally speaking, a transfer of regional industrial transfer is not the entire industry, but is associated with the upgrading of regional industrial structure. If the industrial transfer can be carried out in time, more production factors such as land, capital and labor can be used to develop a industry with a higher level ${ }^{[8]}$.

(2) Effect of industrial transfer on the accepted region. As far as the accepted region is concerned, the industrial transfer not only improves the production capacity, but also enhances the competitiveness of the whole region through the diffusion transfer mechanism ${ }^{[9]}$. When a industry transfers from the developed areas to under developed areas, usually accompanies with the transfers of advanced production factors, such as a large amount of capital, technology and knowledge, 
resulting in a rapid accumulation of production factors which is relatively scarce before ${ }^{[10]}$. At the same time, the industrial relocation promotes the technology diffusion and increases the employment opportunities.

\section{The concept of industrial transfer cost and its control}

\subsection{The concept of industrial transfer cost}

The cost of industrial transfer means the economic value which is needed to pay in order to complete the industrial transfer ${ }^{[11]}$. For the transferred and accepted region of industry, both of them need to pay the industrial transfer cost. The types of the industrial transfer cost are listed in table 1.

Table 1 The types of industrial transfer cost

\begin{tabular}{ll}
\hline \multicolumn{1}{c}{ Types of industrial transfer cost } & \multicolumn{1}{c}{ Factors influencing the cost } \\
\hline Production cost & Land, labor force, materials, etc \\
Transportation cost & $\begin{array}{l}\text { Transportation cost among enterprises, raw } \\
\text { materials source and market } \\
\text { Management mode, government support, } \\
\text { Institutional cost }\end{array}$ \\
market system, fiscal and taxation system \\
Costs due to environmental pollution, social \\
\\
costs caused by structural unemployment
\end{tabular}

For the transferred region, the industrial transfer cost including the sunk cost due to giving up some of the fixed assets as well as the cost of production factor fluidity. For the accepted region, the industrial transfer cost includes the opportunity cost due to the infrastructure for attracting investment as well as the social cost caused by transferred industry. Judging from the present condition, the environmental pollution is the main social cost. The industrial transfer cost is an important question for both transferred and accepted region, moreover, only the transfer income is greater than the transfer cost, the industrial transfer is reliable.

\subsection{Control of industrial transfer cost}

\subsubsection{The cost control for transferred region}

(1) Reducing the delay cost for industrial transfer. If the developed region delays the industrial transfer, it may lose the best chance for industrial upgrading and structural adjustment, leading to a serious delay $\operatorname{cost}^{[12]}$.

(2) Reducing the social cost. It is necessary to should strengthen personnel training in the transferred region in order to reduce the structural unemployment.

\subsubsection{The cost control for accepted region}

(1) Reducing the circulation cost of production factors. The circulation channels of various production factors should be kept open. The government needs to increase the investment in science and technology field so as to improve the conditions of research and production, and to make the enterprise become the real master for science research.

(2) Strengthening the regional environmental monitoring. The Midwest China cannot put down the threshold of environmental protection, cannot indiscriminately introduce an industry with high pollution and high energy consumption. The environmental cost should be included in the total cost of industrial transfer. This is not only the inherent requirement of financial accounting, but also 
is an ecological protective screen of industrial transfer.

\section{Acknowledgements}

The research was funded by the key accounting research project from 2017 to 2018 of Financial Bureau of Tianjin and the Accounting Society of Tianjin, China (No. Y170902).

\section{References}

[1] H. Chen. An Analysis of the industry benefits in the eastern China since the reform and opening-up. Journal of Wuhan University of Technology (Social Science Edition), 23 (2010)318-322.

[2]He Jiefeng. Driving factors of Guangdong’s economic growth: 1978-2012. A dissertation submitted for the degree of master, South China University of Technology, Guangzhou, China. May 29, 2014.

[3]G. Zhang, S. Wang, S. liu and S. Jia. Research of the coordinated development of Beijing-Tianjin-Hebei based on the industrial docking and transfe. Economy and management, 28 (2014) 14-20.

[4]Y. Guo, W. Niu. Several problems for undertaking industrial transfer. Chinese High-tech Industries Guide, June 27, 2011, version A03.

[5]D. Gao. Research on the selection of leading industries and mode of undertaking industry transfer. A Dissertation submitted to Hefei University of Technology for the Degree of Philosophy Doctor. September, 2013.

[6] A. Kokko. Technology, market characteristics and spillovers. Journal of Development Economics, 43(1994)279-293.

[7] A. Wu. Industrial transfer is an interaction- Discussion with Sui Guangjun and Guo Nanyun. Reform, 2(2009)143-145.

[8]Tang Q. Study on Guangdong province industrial transfer overflow effect under financial support. A dissertation submitted for the Degree of Doctor, South China University of Technology, Guangzhou, China. June 1, 2011.

[9] W. Li. Financial support for the undertaking of industrial transfer. Chinese Finance, 3(2015)81-82.

[10]X. Liu. Capital reset, redistribution of regional interests and the industry transfer. Economist, 12(2014)92-98.

[11]L. Li, J. Song, E. Liu. Cost analysis of industrial transfer based on regional advantages. Business Economy, 1(2014)19-20.

[12]F. R. Liu, G.Q. Luan, C. Liu. On delayed cost due to the delay in industrial transference. Technology and Innovation Management, 2010, 31(6): 671-673. 